bitten very deep into the consciousness of people in Britain. These fears may not be wholly out of date. Britain is immensely dependent on world trading conditions, and if other countries will not, or cannot, buy our goods, or will not, or cannot, buy the primary commodities of the sterling area countries, recession and unemployment in Britain cannot be prevented. Our best chance of averting the worst consequences of a possible slump is to increase our present strength, and our reserves of strength, by following the doctrine of increased production and productivity.

The more intractable difficulty is the 'group' interest. In trade and industry, there are two clearly marked large groups-management or employers on one hand, workers or trade unionists on the other. Each of these groups itself comprises many other economic groupings. There are often disagreements and rivalries, stresses and strains, between the various component parts of, as well as between, the two groups. It is noticeable, for example, how strongly the pattern of wage claims is influenced by a desire in one industry to maintain its relative position vis-à-vis other industries, as though the existing pattern must be right for all time.

Within the field of economic groupings, each individual will tend to concentrate his attention on the particular section, probably the nearest and smallest to which he belongs, and much less attention on other sections, even those that belong to the same general group. If, too, within each group (that is, management-labour) there are rivalries and dissents, it is the more likely that when the opposing sides meet, at whatever level, it will be in an atmosphere of antagonism or 'againstness'.

As a result there is a danger of opposing for opposing's sake, and of missing the opportunity to construct new ideas to meet new needs. If this view of the group interest is correct, society as a whole, which is the biggest group of all, will get relatively little attention or understanding. Yet it is now the supreme individual interest of everyone to look at the problem of the society as a whole, for now we are concerned with survival as a nation, and failure would bring disastrous economic consequences to all.

How is that understanding and recognition to be brought about? One way might be in small discussion groups of people in the same factory or shop. If anything of this kind were to be tried, it would have to be carefully prepared, and the people who led these discussions would have to be people of very high calibre. It would also have to be done with the complete goodwill of the management and of the union concerned.

The other main feature of the annual conference of the British Institute of Management is a series of sectional meetings at which topics of particular concern to personnel officers are considered. This year four such meetings were held, and were arranged on experimental lines in order to secure maximum 'audience participation'. The matters discussed were the use of wages as an incentive to higher production, the means of securing co-operative attitudes from workers, personnel management as a career and the improvement of selection methods for unskilled workers. The experiments, which copied techniques borrowed from the United States, were sufficiently successful to merit further trials.

\section{THE CRAFTSMAN IN THE ENGINEERING INDUSTRIES}

A PRESIDENTIAL address delivered to one of the major professional institutions is normally devoted to the subject which has engaged the greater part of its author's career, and not unnaturally the study of man and men is therefore a frequent theme. In his presidential address on October 16 to the Institution of Mechanical Engineers, Mr. A. Roebuck turned his attention to the importance of the craftsman in industry, the necessity of the professional engineer recognizing his importance, and the necessity for the craftsman to be taught more of the scientific principles upon which his trade is based. With these sentiments no one can quarrel; but when Mr. Roebuck suggests that ". . . without the craftsman ... the work of professional engineers and technicians would be of no avail, but, on the other hand, if the craftsman is left to himself he will produce an answer", an emphatic protest must be made. The double training of the professional engineer, so rightly insisted upon by the major institutions, makes it possible for him to learn rapidly any craft that he may need to master, while frequently enabling him to devise methods of manufacture which do not call for craftsmanship. The state of development of the mechanical engineering industry compared with that of the electrical industry should serve to underline the dangerous fallacy that is being propounded by Mr. Roebuck, since the former still depends primarily on the craftsman at the bench and the latter on the professionally trained designer.

It is fashionable to deplore the lack of skilled craftsmen and draughtsmen in engineering works to-day, and it seems a pity that Mr. Roebuck in his address did not analyse this very serious problem; it is primarily in the industries which are dependent on the professional engineer and the scientific worker that a major attack on the problem of training craftsmen thoroughly is being made, and that the best craft training schools now exist on a wide scale.

Some twenty years ago another president of the Institution of Mechanical Engineers, Sir Richard W. Allen, wrote a paper in which he directed attention to the very thorough training in craftsmanship given in the German-speaking engineering world, and suggested that it might profitably be introduced in Great Britain. In Britain a boy becomes a "craftsman" by serving a five-year apprenticeship ; in Germany and Switzerland the boy has to pass a trade test at the age of eighteen in order to become a journeyman, and a further test at twenty-one in order to become a master. The examiners are skilled men appointed for the district, and the apprentice must produce detailed note-books showing sketches and descriptions, duly signed by his foreman, of every job that he has done. Many members of the teams that visited German industry at the end of the Second World War were struck by the pride taken by German works-managers and directors, more often than not graduate engineers themselves, in their training shops, which were to be found even in the smallest firms.

If, as Mr. Roebuck maintains and all will surely agree, the skilled craftsman in a works is all-important, why is he not treated as such and put on the staff? Admittedly the attitude of the trade unions has not been helpful when the idea has been raised; but every engineer must have been disturbed at some 
time or another by the privileges enjoyed by junior office-workers in comparison with those accorded to tried servants of the company "on the clock".

An analogous position is to-day to be found in most drawing offices. At the top are skilled mechanical designers, mostly in their late fifties or sixties; but where are their successors? The men who should be following them started as apprentices in the shops, took the first opportunity to get out of the shops into the drawing office, and then proceeded by dint of hard work to qualify as associate members of one of the Institutions; this opened the door to 'design', sales and all the other apparently more lucrative and socially more attractive avenues in the company. Until the importance and the difficulty of first-class mechanical design-work on the drawing board is recognized in terms of both salary and status, the situation can only continue to decline, while professional engineers and scientific workers become ever more frustrated at the lack of men able to translate their basic concepts into hardware without constant supervision.

The old methods of training craftsmen both in the shops and drawing office depended essentially on time. During the War the Ministry of Labour training centres, making use of the work of Sir Frederic Bartlett, showed that by modern methods of selection and training a degree of skill could be attained by men and women in times that make nonsense of the old conception of the five-year apprenticeship. One looks forward to the day when it will be possible to review a presidential address describing the success of a large firm in applying scientific methods to the selection and training of its men.

D. B. WeLbourn

\section{FORECASTING WEATHER FROM SOLAR RADIATION}

$\mathrm{M}$ ORE than seventy years ago Dr. S. P. Langley began measurements of the solar radiation and its spectrum. By 1902 his results had led him to the belief that the so-called 'solar constant' was in fact a variable, and that its variations might be an important factor in terrestrial weather. In 1905 the research was taken up by C. G. Abbot, who has continued it ever since with single-minded devotion. In the second of the two papers here under consideration*, he sums up his conclusions, in an endeavour to persuade meteorologists to abandon their general scepticism or lack of interest, and at least to give him a fair hearing.

There are several reasons for this scepticism. Measurements of the solar constant have to be made through the atmosphere, and even on high mountains a proportion of it fails to reach the ground. In theory it is possible to estimate the loss by making a series of observations at different solar elevations, but in practice the complex structure of the upper atmosphere makes the results somewhat uncertain, and many meteorologists remain unconvinced that the observed variations are not, in reality, variations of atmospheric absorption. Some even regard the average computed value of the solar constant as too

* Smithsonian Miscellaneous Collection: 122, No. 1, Long-Range Effects of the Sun's Variation on the Temperature of Washington, D.C. (pp. 14; Pub. 4131); 122, No. 4, Solar Radiation, a Leading (Washington, D.C.: Smithsonian Institution, 1953.) low by an amount much larger than the observed variations. Agreement between values obtained in widely different parts of the world has done some. thing to meet this objection, though it is probable that many of the disturbing factors, in the higher layers, are world-wide in extent. But even granted that the solar constant does vary, the variations found by Dr. Abbot are so small-only one or two per cent-that their direct effect on surface temperatures would be barely perceptible. Dr. Abbot counters this by the argument that the terrestrial effects are indirect, associated with changes in the location of the sub-tropical anti-cyclones and prevailing storm-tracks, and the frequency of hurricanes, all of which affect temperature and rainfall.

There is, of course, no doubt that changes do occur on the surface of the sun, and that some of them are more or less periodic-the existence of the sunspot cycle and of solar faculæ is sufficient evidence -and it is reasonable to accept that, along with variations of other types of radiation, such as corpuscular, ultra-violet and radio wave-lengths, they give rise to variations of visible and infra-red solar radiation. But Abbot goes far beyond this by claiming that these variations are strictly periodic, and that they are all harmonics of the double sunspot cycle of $22 \frac{3}{4}$ years. He enumerates at least twentythree such harmonics, ranging from $2 \frac{1}{7}$ months to 272 months. The amplitudes obtained are mostly microscopic, of the order of 0.1 per cent.

Such a complex array would require a rigid mathematical basis to justify its acceptance; but the method by which it is arrived at is crude and can scarcely be described as mathematical at all. From the description, it consists of plotting the data on a long curve, regarding it from a distance, and picking out the dominant periodicity by eye. This is then computed arithmetically and eliminated, the process being repeated until only non-periodic variations are left. Anyone who has worked with periodicities will realize the pitfalls of this graphical analysis, for the eye of faith only too readily sees regularities in the most irregular of curves. The process is bolstered up by dividing the material into sections; but to the critical eye the agreement between the different sections is not very good.

When we turn to the effect of these supposed variations of the solar constant on weather, the impression received is equally dubious. Dr. Abbot himself writes: "it would be quite impossible for meteorologists to discover these regular periodicities iu weather elements had they not first been found in solar variation". The italics are his ; but it is difficult to see how this argument helps his case. In support, he produces a number of curves illustrating various solar periodicities in the temperature of Washington. and the precipitation of Albany, for various seasons and intervals, for high and low sunspot numbers. Some of the series seem chaotic, but some do show an appreciable resemblance, which is enhanced by introducing rather arbitrary shifts of the time scale.

However, one must be fair. No matter how crude Dr. Abbot's methods may appear to a statistician, he has the courage of his convictions. In the first paper he gives a closer study to the monthly temperatures at Washington. In the departures of 1854-1939 from monthly averages, he finds no fewer than twenty periodicities ranging from $4 \frac{1}{3}$ to $45 \frac{1}{2}$ months. These were used as the basis for 'predicting' the departures for 1940-51, which were not used in the calculations 